\title{
Modeling the Structural Shifts in Gross National Product, Imports and Exports with Cubic Spline Regression
}

\author{
C. Necat Berberoğlu and Bahar Berberoğlu
}

\begin{abstract}
In all the countries in which economic crisis were experienced, the economic problems faced in the years of these crisis cause big changes particularly in economic time series of the country. These time series are usually affected by various internal or external events. In some cases such as wars, political and economic crisis, sharp changes and breaks occur in all the economic data collected in their periods, but these time series usually keep their continuity with some structural shifts or structural changes. In this study our attempt was to shed light on the question that, how the economic parameters such as Gross National Product, Exports and Imports which are in interaction, change in the years of economic crisis? Do same structural changes or shifts occur in these parameters always occur at the same time or similarly?

In order to investigate this issue, we used cubic spline regression technique in modeling the relationship between GNP, Exports and Imports, then we showed that how prediction sum of squares residuals statistics can improve the analysis in spline models. So, in the study we exposed that the structural shifts and structural changes occur with same time lags on the chosen economic parameters in Turkey.
\end{abstract}

Index Terms - Cubic spline regression, structural change, PRESS statistics, time series.

\section{INTRODUCTION}

Economic data creates different structure trends over time and they show ups and downs. There may be important reasons for these changes in the trends and structural breaks, such as economic crisis, wars, new legislation and changes in political regime. In the analysis of such series we can take advantage of Cubic Spline Regression Method which is a special genre of the spline methodology.

In 1980-2006 Period, the economic decisions of April 5 were put into implementation in 1994 and in addition 2001 Economic Crisis was experienced in Turkey. These two events created structural breaks in the values of Gross National Product (GNP), Exports and Imports. Generally many economist employ the method of Cointegration in the analysis of such cases. In our study, we especially used the cubic spline regression in order to suggest an alternative statistical analysis method for the researchers working on similar cases.

In the study of Buse A., and Lim L., (1977) [1] and in a study of Tarpey (2000a) [2] the standard cubic spline

Manuscript received October 11, 2016; revised February 6, 2017.

C. Necat Berberoğlu is with the Anadolu University, Open Education Faculty, Yunusemre Campus, Eskişehir/Turkey (e-mail: bdirem@anadolu.edu.tr).

Bahar Berberoğlu is with the Anadolu University, Faculty of Economic and Administrative Sciences, Yunusemre Campus, Eskişehir/Turkey (e-mail: nberbero@anadolu.edu.tr). regression method was used. Furthermore, Tarpey in his study (2000b) [3], proposed that, Prediction Sum of Squares Statistics (PRESS), ensures a good performance in cubic spline models. We also preferred to use PRESS, particularly because of its ability and advantage in calculation of the residuals and demonstrated its superiority when compared with Residual Sum of Squares.

\section{TURKISH ECONOMY AND FOREIGN TRADE IN THE PERIOD OF 1980-2006}

The rapid economic development in Turkey which started in early $1960 \mathrm{~s}$ with the implementation of planned industrialization and modernization model based upon import substitution strategy, has turned into a severe crisis as a result of the adjustment problems and the oil crisis of 1970s. In the beginning of crisis period the growth rate slowed down then turned negative, inflation began to increase, finding funds for imports became harder and scarcity of many goods emerged in the internal markets, and Turkey had almost came to an end in 1980 .

The Stability Measures which were implemented on 24th of January 1980, aimed maintaining short-term economic stability, structural reconstruction in the economy, and changing long-term accumulation regime. Even though IMF had been supported stability programs implemented before 1980 in Turkey, after the military coup of 12 September 1980 , the relations with IMF altered and the 24th of January program and its results changed in content and influences. The structural adjustment policies of the IMF and World Bank became the major determinants of Turkey's economic policies in the early 1980 s.

International trade played a minor role in the Turkish economy before 1980, but grew rapidly after the 1980 reforms. Especially exports and imports started to increase rapidly after 1983 with the "Government Change". New government emphasized foreign trade liberalization. After 1983 economic reforms promoted foreign trade by removing price controls, decreasing subsidies, reducing tariffs. In addition to rapid growth both in exports and imports, the reforms brought a change in the structure of foreign trade, and the predominant role of agricultural products came to an end with the emergence of a greater emphasis on industrial products.

Turkey signed a free trade agreement with the European Free Trade Association (EFTA) in 1991. In 1992, Turkey and 10 other nations in the Black Sea region formed the Black Sea Economic Cooperation Organization. Turkey became a member of the World Trade Organization (WTO) in 1995, and a year later signed a Customs Union Agreement with the 
EU. Turkey also became a member of the Organization for Economic Cooperation and the Organization of the Islamic Conference. Separately, Turkey has entered into free trade agreements with Israel, and with several Central and Eastern European countries.

During these developments in Turkey's international relations, Turkish Economy experienced several economic crises' and implemented several stabilization programs. Some of these economic crises' emerged from domestic political problems and government changes and some others arise from wars in border countries and international crises. All of these developments had great impacts on Turkey's exports and imports. The most important stabilization programs in 1983-2007 period were, 5th of April 1994 Stabilization Program which had impacts in the same year, and 21st of January 2001 Stabilization Program whose impacts were seen in 2002 .

OF course the major economic effects of all these events were seen on the values of Turkey's Gross National Product (GNP), Exports and Imports.

The relations or interactions between GNP and exports and imports had always been good topics for economic discussions. According to economic theory and practice, the growth of GNP generally causes increases in both exports and imports. But these expected increases can usually be explained with different impacts. Exports values can rise due to the growth in GNP because of the increases in the quality and production amounts of the goods which can be exported. Imports of a country rise simply because of the increases in the national income which will be achieved according to the growth in GNP.

On the other hand, the increases in the values of exports and imports of a country may have great impacts on GNP. The increases in exports directly cause growth in GNP and national income, and of course the increases in imports usually generate diverse effects.

The direction of the causality between economic growth and exports has always been an important and basic research area for the economists who are interested in foreign trade and economic growth. In their study Özer and Erdogan (2007) [4], presented wide literature survey of the studies on this subject and they evaluated some of these works. When the studies mentioned by these authors are investigated, it can be seen that the researchers reached different results for different countries. In all of the studies held by Abou-Stait (2005) [5], Keong, Yusop ve Liew (2002) [6], Awokuse (2003) [7], Ram (2003) [8], Sharma and Panagiotidis (2004) [9] and Medina-Smith (2001) [10] the researchers found that the increases in exports cause economic growth.

On the other hand, Konya (2004) [11] in his study, could not find any causality between exports and economic growth in Holland and Luxemburg, but he found causality from economic growth towards exports in Canada, Japan and South Korea. He also found causality from exports to economic growth in Iceland, and at last he found two sided causality between economic growth and exports in England and Sweden. Abdulnasser and Manuchehr (2000) [12] investigated the hypothesis of economic growth under the priority of exports in Ireland, Mexico, Portuguese, Turkey and Greece, and found a long run relation between economic growth and exports except in Turkey and Greece. They reached to the result that in Mexico and Ireland increases in the exports augmented economic growth but in Portuguese economic growth accelerated exports. Özmen, Özer and Türkyilmaz (1999) [13] in their studies found a one sided causality from exports towards economic growth.

As explained above the relations between exports and economic growth were analyzed for many countries by many researchers. In all of these studies the causality between exports and economic growth was emphasized and investigated.

But in this study, our first attempt shall be trying to find out whether economic crises affect the relationship between GNP, exports and imports. Our second attempt shall be observing whether the structural changes or shifts in these parameters are same or occur similarly.

In the years of economic crises and devaluations almost all of the economic parameters of Turkish Economy were affected negatively but usually at different degrees and with different time lags. When the values of GNP, exports and imports are considered our assumption was that, they were influenced similarly and the structural changes occurred in data without any time lag. So we proposed that, the devaluation in the year of 1994 and the 2001 Economic Crisis were the most important events of 1980-2006 period in Turkish Economy and the structural changes in the values of GNP, exports and imports occurred in these years. For this reason we applied cubic spline regression on these three parameters and formed the knots $t_{1}=15$ for 1994 and $t_{2}=22$ for 2001.

\section{Model (CubIC Spline REGRESSION AND PRESS STATISTICS)}

Spline regressions are splines which are computed according to a regression model. The model is generally as follows,

$$
\begin{gathered}
y_{i}=s_{\Delta}\left(x_{i}\right)+\varepsilon_{i}, \quad i=1,2, \ldots, n \\
y_{i}=\sum_{j=0}^{m} \beta_{0 j} x_{t}^{j}+\sum_{k=1}^{N} \sum_{j=0}^{m} \beta_{k j}\left(x_{i}-t_{k}\right)_{+}^{j}+\varepsilon_{i} .
\end{gathered}
$$

The degree of the spline function, $\mathrm{m}$, depends on what is a realistic assessment of the number of derivatives available in the regression function. Obviously, this knowledge is frequently not available. Often the choice is simply $m=3$, which yields a cubic spline and which is the smallest $\mathrm{m}$ yielding visual smoothness. The choice $m=2$ or $m=1$ will yield, respectively, piecewise quadratics or piecewise lines (i.e., quadratic and linear splines) [14].

The cubic spline function is

$$
y_{i}=\sum_{j=0}^{3} \beta_{0 j} x_{t}^{j}+\sum_{k=1}^{N} \sum_{j=0}^{3} \beta_{k j}\left(x_{i}-t_{k}\right)_{+}^{j}+\varepsilon_{i}
$$

Formula (3.3) may be rewritten as follows:

$$
E\left(y_{i}\right)=\left\{\begin{array}{cc}
\beta_{00}+\beta_{01} x+\beta_{02} x^{2}+\beta_{03} x^{3} & , 0<x \leq t_{1} \\
\beta_{10}+\beta_{11}\left(x-t_{1}\right)+\beta_{12}\left(x-t_{1}\right)^{2}+\beta_{13}\left(x-t_{1}\right)^{3} & , t_{1}<x \leq t_{2} \\
\beta_{20}+\beta_{21}\left(x-t_{2}\right)+\beta_{22}\left(x-t_{2}\right)^{2}+\beta_{23}\left(x-t_{2}\right)^{3} & , t_{2}<x
\end{array}\right.
$$


The PRESS residual for the leave-one-out analysis using the restricted least squares fit is

$$
\tilde{e}_{i}=y_{i}-\tilde{y}_{i} .
$$

It can be expressed

$$
\tilde{e}_{i}=\frac{y_{i}-\tilde{y}_{i}}{1-h_{i i}+j_{i i}},
$$

where $j_{i i}$ denote the $i$ th diagonal element of the matrix $J$ [2], [3].

\section{ESTIMATION RESULTS: GNP, EXPORTS AND IMPORTS CSR MODELS}

First, we estimated the coefficients of the models of GNP, exports and imports by using ordinary least squares method (OLS) to compare them with CSR models based on RSS and PRESS statistics. Then we estimated the RSS values of OLS models which were necessary in determining the significance of $\mathrm{F}$ statistics.

Following equations are the OLS estimates of the coefficients of GNP, exports and imports.

\begin{tabular}{|c|c|c|c|c|}
\hline \multicolumn{2}{|c|}{$\begin{array}{l}\text { Coefficients of } \\
\text { OLS Models }\end{array}$} & GNP & EXP & IMP \\
\hline $\begin{array}{l}n \\
\bar{v} \\
x \\
v\end{array}$ & $\begin{array}{l}\beta_{00} \\
\beta_{01} \\
\beta_{02} \\
\beta_{03}\end{array}$ & $\begin{array}{l}48008536.83 \\
22587745.50 \\
93626.21 \\
-751.56\end{array}$ & $\begin{array}{l}2668733.09 \\
732044.27 \\
31893.18 \\
-1349.15\end{array}$ & $\begin{array}{l}7642904.85 \\
456730.91 \\
-20731.66 \\
6725.14\end{array}$ \\
\hline $\begin{array}{l}\stackrel{v}{N} \\
x \\
x \\
n \\
n\end{array}$ & $\begin{array}{l}\beta_{10} \\
\beta_{11} \\
\beta_{12} \\
\beta_{13}\end{array}$ & $\begin{array}{l}-17169565.02 \\
8974746.16 \\
-1420263.33 \\
33321.95\end{array}$ & $\begin{array}{l}-1911223.20 \\
4294324.04 \\
-610680.15 \\
28275.87\end{array}$ & $\begin{array}{l}-36356534.22 \\
34306936.67 \\
-9134782.95 \\
659269.06\end{array}$ \\
\hline $\begin{array}{l}\stackrel{x}{v} \\
\stackrel{N}{N}\end{array}$ & $\begin{array}{l}\beta_{20} \\
\beta_{21} \\
\beta_{22} \\
\beta_{23}\end{array}$ & $\begin{array}{l}-12768950.62 \\
2327606.44 \\
2975828.01 \\
-226688.03\end{array}$ & $\begin{array}{l}6939822.17 \\
-8943457.96 \\
5967597.36 \\
-532261.94\end{array}$ & $\begin{array}{l}-8448646.36 \\
-22807724.06 \\
3627504.99 \\
-1378432.40\end{array}$ \\
\hline
\end{tabular}

TABLE I: COEFFICIENTS OF OLS MODELS FOR GNP, EXPORT AND IMPORT

While forming cubic spline regression models, join points or knots appeared in the years of structural changes. For this reason when we estimate the equation (3.4), our data set knots appeared at $t_{1}=15$ and $t_{2}=22$. So the equation could be written as below,

$$
E\left(y_{i}\right)=\left\{\begin{array}{cc}
\beta_{00}+\beta_{01} x+\beta_{02} x^{2}+\beta_{03} x^{3} & , 0<x \leq 15 \\
\beta_{10}+\beta_{11}(x-15)+\beta_{12}(x-15)^{2}+\beta_{13}(x-15)^{3} & 15<x \leq 22 \\
\beta_{20}+\beta_{21}(x-22)+\beta_{22}(x-22)^{2}+\beta_{23}(x-22)^{3} & , 22<x
\end{array}\right.
$$

All of the coefficients of the CSR model estimated according to the equations (3.4) and (4.1) can be expressed as below,

Intercept: $\beta_{00}+\beta_{10}-\beta_{11} t_{1}+\beta_{12} t_{1}^{2}-\beta_{13} t_{1}^{3}+\beta_{20}-\beta_{21} t_{2}+\beta_{22} t_{2}{ }^{2}-\beta_{23} t_{2}^{3}$

Coefficient of $x$ : $\beta_{01}+\beta_{11}-2 \beta_{12} t_{1}+3 \beta_{13} t_{1}^{2}+\beta_{21}-2 \beta_{22} t_{2}+3 \beta_{23} t_{2}^{2}$

Coefficient of $x^{2}: \beta_{02}+\beta_{12}-3 \beta_{13} t_{1}+\beta_{22}-3 \beta_{23} t_{2}$

Coefficient of $x^{3}: \beta_{03}+\beta_{13}+\beta_{23}$

The coefficients for $x^{2}$ and $x^{3}$ given above must be zero in order for the response in the structural changes to be linear.

The estimated CSR coefficients of GNP, exports and

\begin{tabular}{|c|c|c|c|c|}
\hline \multicolumn{2}{|c|}{$\begin{array}{l}\text { Coefficients of } \\
\text { OLS Models }\end{array}$} & GNP & EXP & IMP \\
\hline $\begin{array}{l}n \\
\vec{v} \\
\vec{x} \\
v\end{array}$ & $\begin{array}{l}\beta_{00} \\
\beta_{01} \\
\beta_{02} \\
\beta_{03}\end{array}$ & $\begin{array}{l}48050113.17 \\
2230302.86 \\
98211.84 \\
-955.36\end{array}$ & $\begin{array}{l}2797674.13 \\
643744.93 \\
46114.62 \\
-1981.19\end{array}$ & $\begin{array}{l}7460194.75 \\
581851.51 \\
-40883.51 \\
7620.78\end{array}$ \\
\hline 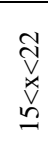 & $\begin{array}{l}\beta_{10} \\
\beta_{11} \\
\beta_{12} \\
\beta_{13}\end{array}$ & $\begin{array}{l}-18341161.70 \\
10348891.61 \\
-1812650.19 \\
66555.84\end{array}$ & $\begin{array}{l}-5544706.05 \\
8555973.11 \\
-1827592.88 \\
131344.44\end{array}$ & $\begin{array}{l}-31207870.86 \\
28268158.63 \\
-7410411.53 \\
513220.39\end{array}$ \\
\hline $\begin{array}{l}\vec{v} \\
\vec{N}\end{array}$ & $\begin{array}{l}\beta_{20} \\
\beta_{21} \\
\beta_{22} \\
\beta_{23}\end{array}$ & $\begin{array}{l}-18453436.26 \\
8266440.02 \\
576621.12 \\
-65600.48\end{array}$ & $\begin{array}{l}-8253100.69 \\
6409830.46 \\
-457906.77 \\
-129363.25\end{array}$ & $\begin{array}{l}-22918416.43 \\
720061.77 \\
-2266780.92 \\
-520841.16\end{array}$ \\
\hline $\begin{array}{l}\mathrm{F} \\
\mathrm{R}^{2}\end{array}$ & & $\begin{array}{l}.443 \\
0.9997\end{array}$ & $\begin{array}{l}13.6321 \\
0.9988\end{array}$ & $\begin{array}{l}3.7981 \\
0.9982\end{array}$ \\
\hline
\end{tabular}
imports models are presented in Table II.
TABLE II: COEFFICIENTS OF CSR MODELS FOR GNP, EXPORT AND IMPORT

As shown in Table II, all of the GNP, export and import models are statistically significant at 0.05 levels. Then we needed to compute $y$ values of these models and showed their observed and estimated values in Fig. 1, 2 and 6. By this way the accordance of the results of CSR model with the observed values of GNP, exports and imports could be seen easily.

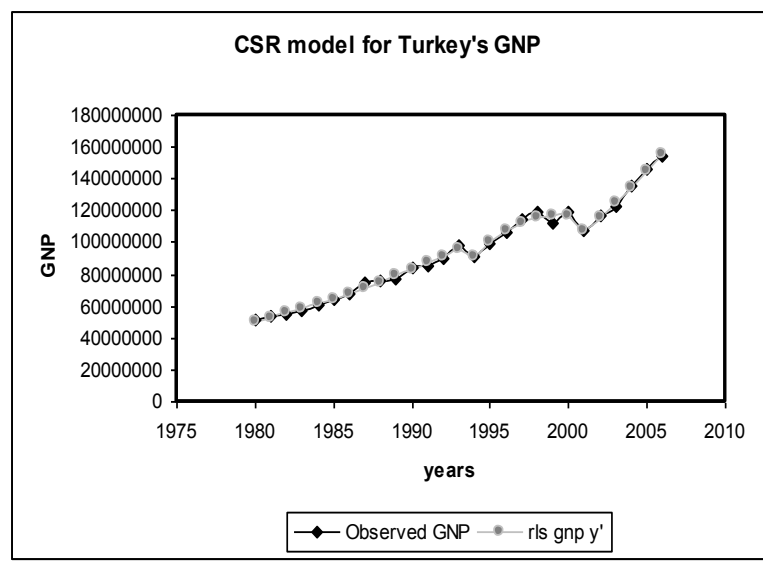

Fig. 1. CSR model for Turkey’s GNP 1980-2006.

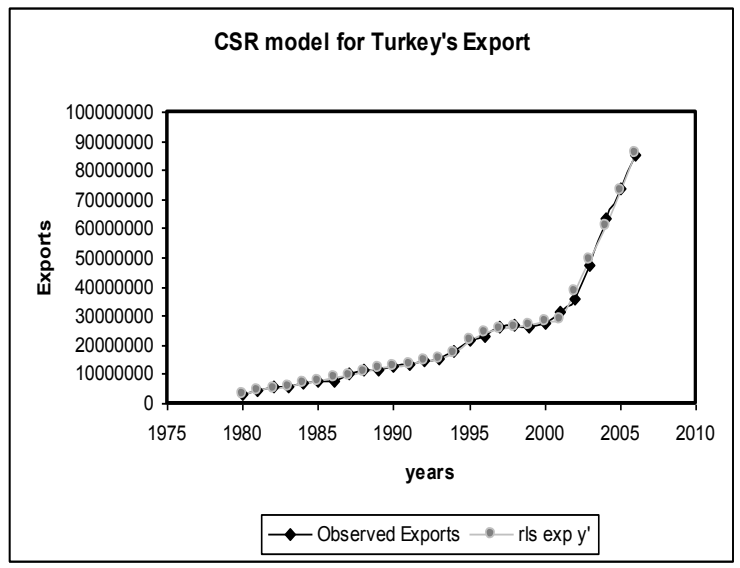

Fig. 2. CSR model for Turkey's Export in 1980-2006.

According to Fig. 1 we do not observe any break point in the GNP increase from 1980 to1993 then, for only one year GNP declines in the crisis year of 1994. The continuous increase appears in 1995-2000 period, and another decline occurs in the crisis year of 2001 and after 2002 the increase in GNP becomes greater. By considering these crisis years, knots are formed in our CSR model, so as seen in the same 
figure the graphics of our model fitted observed GNP graphics almost exactly.

In Fig. 2 the increase of exports in the period of 1980-1993 seems to be slight but continuous and over the period of 1994-2001 the value of exports fluctuates and after 2001 a sharp rise appears till 2006. Again by considering these changes knots are formed in our CSR model and the graphics of our model fitted observed exports.

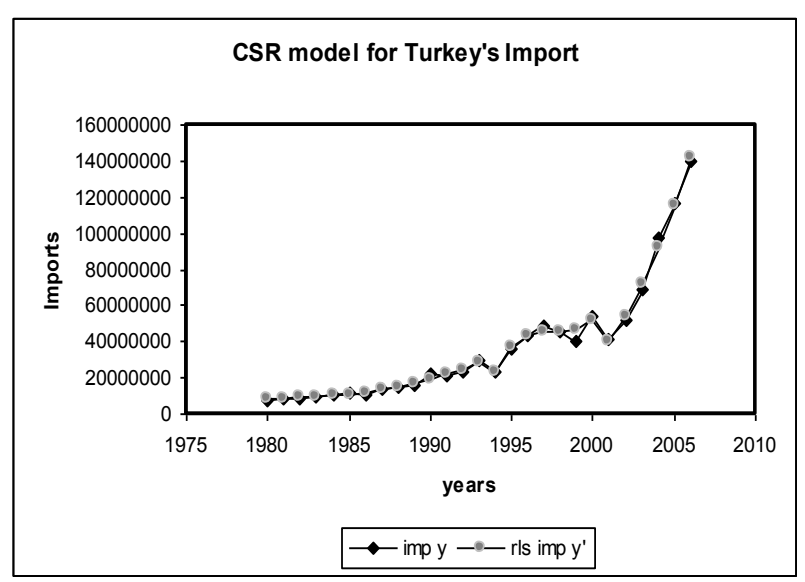

Fig. 3. CSR model for Turkey's Import in 1980-2006.

In Fig. 3, we can easily see that the increase of imports in the period of 1980-1993 is very slow but continuous, and between the years 1994-2001 the value of imports seems to be unstable and fluctuating, and after the year of 2001 a sharp increase is seen till 2006. Also here by considering these changes, knots are formed in our CSR model and the graphics of our model fitted observed imports.

When we examine the graphics of these three models we can see the great difference among them. But we observe similar structural changes in these parameters in the same crisis years, because of the interaction between them. For this reason, the restriction matrices used for obtaining CSR model and $\mathrm{X}$ matrices for time was same in the models, and knots of them were similar.

We designed Table III to explain and show the significance of the models which we constructed by using prior information about determining the knots according to residual sum of squares. We also showed how PRESS statistics can do much better job in CSR models in the same table. Of course, the OLS model will produce a lower error sum of squares, but one may expect that the model with the linear restrictions will perform better.

TABLE III: COMPARISON OF CSR MODELS AND OLS MODELS WITH RESIDUALS SUM OF SQUARES

\begin{tabular}{|c|c|c|c|}
\hline \multicolumn{2}{|c|}{$\begin{array}{l}\text { Residuals sum of squares of } \\
\text { Constructed CSR Models and } \\
\text { OLS Models }\end{array}$} & \multirow{2}{*}{$\begin{array}{l}\mathrm{RSS} \sum e_{(i)} \\
8,97314 \mathrm{E}+13\end{array}$} & \multirow{2}{*}{$\begin{aligned} \operatorname{PRESS} \sum \tilde{e}_{(i)} \\
3,48672 \mathrm{E}+14\end{aligned}$} \\
\hline GNP & CSR Model & & \\
\hline & OLS Model & 8,69011E+13 & $1,18938 E+15$ \\
\hline \multirow[t]{2}{*}{ Export } & CSR Model & $3,14454 \mathrm{E}+13$ & $1,40148 E+14$ \\
\hline & OLS Model & $1,11603 E+13$ & $1,96724 \mathrm{E}+14$ \\
\hline \multirow[t]{2}{*}{ Import } & CSR Model & $1,20163 \mathrm{E}+14$ & $5,70533 \mathrm{E}+14$ \\
\hline & OLS Model & $7,97679 \mathrm{E}+13$ & $1,36585 \mathrm{E}+15$ \\
\hline
\end{tabular}

In order to test the significance of the CSR model constructed in Table III and to obtain a positive $\mathrm{F}$ test statistical value, the RSS value of CSR model should be greater than the RSS of OLS model. As a matter of fact three models above are all significant at 0.05 levels. But according to Tarpey's [2], [3] approach the PRESS statistics of CSR model should be smaller than OLS model in order to obtain the significant restrictions which are determined according to the knots. Here it can be seen that, all of our three CSR models are smaller than the PRESS statistics of OLS models.

Many econometrics text books suggest that the RSS value of CSR model must be greater than OLS model in order to obtain positive $\mathrm{F}$ value and significant restrictions. But according to Tarpey's [2], [3] approach, PRESS statistics has a better performance in CSR models and if some restrictions were added, PRESS value of CSR model should be smaller than the PRESS value of OLS model and in this case it could be possible to put forward that the restrictions are significant. As a matter of fact, all of these arguments are summarized and show in Table III, and consequently it can be seen in the same table that the restrictions used in both approaches are significant.

\section{CONCLUSION}

The economic issues and problems experienced in a country cause big changes particularly in economic time series. They are usually affected by various internal or external events. Such cases as wars, economic or politic crises generally cause abrupt and sharp changes in the data collected in their periods but these time series usually keep their continuity with some structural shifts or structural changes.

In this study our attempt was to shed light on the question that, how the economic parameters such as Gross National Product, Exports and Imports which are in interaction, change in the years of economic crisis? Do same structural changes or shifts occur in these parameters similarly?

In the years of economic crises and devaluations almost all of the economic parameters of Turkish Economy were affected negatively but the effects on many parameters were usually at different degrees and some parameters were affected with different time lags. When the values of GNP, exports and imports are considered our assumption was that, they were influenced similarly and the structural changes occurred in data without any time lag. So we proposed that, the devaluation in the year of 1994 and the 2001 Economic Crisis were the most important events of 1980-2006 period in Turkish Economy and the structural changes in the values of GNP, exports and imports occurred in 1994 and 2001. For this reason we applied cubic spline regression on these three parameters and formed the knots $t_{1}=15$ for 1994 and $t_{2}=22$ for 2001.

In our study we used cubic spline regression model in order to expose how the economic policies which were implemented to promote Turkish foreign trade caused structural changes in related data. With this effort we realized that the devaluation in 1994 and the big economic crisis experienced in 2001 caused similar and synchronous structural shifts in GNP, exports and imports. So we noticed that as in our assumption above, these three parameters which are in interaction were influenced in 1994 and 2001 similarly and the structural changes occurred in without any time lag. 
In the study we demonstrated how Cubic Spline Regression (CSR) becomes a very useful tool in the existence of structural shifts or changes in time series, we also showed that that prediction sum of squares residuals (PRESS) statistics improve the analysis in cubic spline models. Buse and Lim (1977) [1] anyway showed the equality of Restricted Least Squares and Cubic Spline Regression before, we gave the proof that the values which were estimated with PRESS statistics fit $\hat{y}$ values in the case of $R \beta=0, \hat{y}$. As we explained in the appendix estimating similar $\hat{y}$ values in both approaches may be important for statisticians and to take benefit especially from PRESS statistics can also be advised to econometricians. The interactions among GNP, exports and imports is a well-known subject in economics and they are analyzed with various models, but if great structural shifts occur in these parameters in the cases of big economic crises and devaluations cubic spline models which describe the break points as knots can do better job in estimations. The models in this study will be more useful in understanding the real effects of economic crises in a country and they will be helpful in realizing whether the size and length of crises are exaggerated or experienced in reality.

\section{REFERENCES}

[1] A. Buse and L. Lim, "Cubic Splines as a Special Case of Restricted Least Squares," Journal of the American Statistical Association, vol. 72, no. 357, pp. 64-68, 1977.

[2] T. Tarpey, "Spline bottles," The American Statistician, vol. 54, no. 2, pp. 129-135, 2000a.

[3] T. Tarpey, "A note on the prediction sum of squares statistic for restricted least squares," The American Statistician, vol. 54, no. 2, pp. $116-118,2000 b$

[4] M. Özer and L. Erdogan, "Time series analysis of exports, imports and economic growth in Turkey," Economic Approach, 2007.

[5] F. Abou-Stait, "Are exports the engine of economic growth? An application of cointegration and causality analysis for Egypt, 1977-2003," African Development Bank Economic Research Working Paper No 76, pp. 1-21. July 2005.

[6] C. C. Keong, Z. Yusop, and V. K. Liew. (2002). Export-led growth hypothesis in Malaysia: An Application of two-stage least square technique. pp. 1-21. [Online]. Available: http://econwpa.wustl.edu:8089/eps/if/papers/0308/0308002.pdf

[7] T. O. Awokuse, "Is the export-lead growth hypothesis valid for Canada?" Canadian Journal of Economics, vol. 36, no. 1, pp. 126-136, March 2003

[8] Y. Ram, "Am empirical examination of the export-led growth hypothesis in Fiji," Economics Department of Reserve Bank of Fiji, Economics Department Working Paper 2003/01, pp. 1-39, 2003

[9] A. Sharma and T. Panagiotidis. (2004). An analysis of exports and growth in India: Integration and causality evidence (1971-2001). [Online]. $1-22$ pp. Available: http://www.lboro.ac.uk/departments/ec/Reasearchpapers/2004/Sharm aIndia_RDE.pdf
[10] E. J. Medina-Smith,'Is the export-led growth hypothesis valid for developing countries? A case study of costa rica," United Nations Conference on Trade and Development Policy Issues in İnternational Trade and Commodities Study Series No. 7, Newyork and Geneva, pp. 1-57, 2001.

[11] L. Konya, "Export-led growth, growth-driven export, both or none? Granger causality analysis on OECD countries," Applied Econometrics and International Development, AEEADE, vol. 4, No.1, pp. 73-94, 2004.

[12] H. J. Abdulnasser and I. Manuchehr, "Export performance and economic growth causality: An empirical analysis," Atlantic Economic Journal, Springer, International Atlantic Economic Society, vol. 28, no. 4, pp. 412-426, December 2000.

[13] A. Özmen, M. Özer, and S. Türkyılmaz, "The causality between economic growth and exports in Turkey," Marmara University, Publication No. 640, İstanbul, pp. 379-392, 1999.

[14] E. J. Wegman and I. W. Wright, "Splines in statistics," Journal of the American Statistical Association, vol. 78, no. 382, pp. 351-365, 1983.

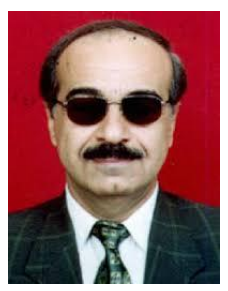

Cafer Necat Berberoğlu was born on February 25 1950 in Seyitgazi / Eskişehir. Turkey. He got the full professor degree in economic theory from Higher Education Board of Turkey, University of Assignment: Anadolu University, Faculty of Economical and Administrative Sciences in 1987

As seen above, he achieved his last academic title in 1987 (Almost 30 years ago). Prof. Berberoğlu, in an academic life which is more than 40 years published more than 20 text and research books in his native language and numerous articles, working papers and etc.

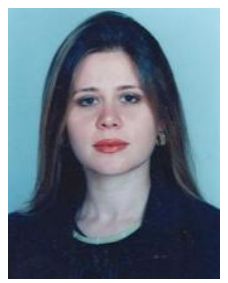

Bahar Berberoğlu was born on March 15, 1973in Eskisehir, Turkey. She graduated with a bachelor of statistics, her research field is in statistics from Anadolu University, Faculty of Science, Department of Statistics in 1994; she postgraduated in the field of statistics from Graduate School of Sciences, Anadolu University in 1998; PhD degree in the field of statistics from Graduate School of Sciences, Anadolu University in 2006.

She is now associate professor in quatitative methods in Anadolu University, Open Education Faculty from 2013.

Her areas of interest are spline methodology, Turkish economic history, Turkish foreign policy, economic crises, European Union, information economy, open and distance education, lifelong learning.

She has published: B. Berberoğlu, "Social capital and lifelong education in the European union and Turkey," International Journal of Business, Humanities and Technology, vol. 6, no. 2, pp. 9-16, 2016.

B. Berberoğlu and C. N. Berberoğlu, "Is Turkey ready for global network in the perspective of European union?" Journal of Statistical Science and Application, vol. 4, no. 9-10, pp. 205-214, October 2016.

B. Berberoğlu, "The analysis of the effects of military coups on gross national product in Turkey: 1950-1984," Romanian Journal of Political Science, PolSci, vol. 16, no. 1, Summer 2016. 